\title{
Publisher Correction: The current state and future directions of RNAi-based therapeutics
}

\author{
Ryan L. Setten, John J. Rossi and Si-ping Han (1)
}

Nature Reviews Drug Discovery (2019) https://doi.org/10.1038/s41573-019-0017-4

Published online 7 March 2019

The use of the names for patisiran has been made consistent throughout the article in line with the journal style and typographical errors have been corrected.

https://doi.org/10.1038/s41573-019-0023-6 I Published online 18 March 2019

\section{Author Correction: Therapeutic strategies for hepatitis B virus infection: towards a cure}

Gregory C. Fanning, Fabien Zoulim (D), Jinlin Hou and Antonio Bertoletti (D)

Nature Reviews Drug Discovery 18, 827-844 (2019) https://doi.org/10.1038/s41573-019-0037-0 Published online 27 Aug 2019

In Box 1, citations and text regarding the prevalence of hepatitis B virus in China have been corrected, and routes of transmission have been clarified. This correction has been made to the online version of the review.

https://doi.org/10.1038/s41573-019-0057-9 I Published online 8 January 2020

๑) Springer Nature Limited 2020

\section{Publisher Correction: Breast cancer drug approvals by the US FDA from 1949 to 2018}

Chandra P. Leo, Cornelia Leo and Thomas D. Szucs

Nature Reviews Drug Discovery 19, 11 (2020) https://doi.org/10.1038/d41573-019-00201-w Published online 20 November 2019

The author affiliations in the pdf were incorrect. These have now been corrected in the online pdf.

https://doi.org/10.1038/s41573-020-0060-1 I Published online 14 January 2020

(c) Springer Nature Limited 2020

\section{Publisher Correction: Therapies for rare diseases: therapeutic modalities, progress and challenges ahead}

Erik Tambuyzer, Benjamin Vandendriessche, Christopher P. Austin, Philip J. Brooks, Kristina Larsson, Katherine I. Miller Needleman, James Valentine, Kay Davies (D), Stephen C. Groft, Robert Preti, Tudor I. Oprea (D) and Marco Prunotto iD

Nature Reviews Drug Discovery (2019) https://doi.org/10.1038/s41573-019-0049-9 Published online 13 December 2019

Errors in the authors' affiliations have been corrected and the acknowledgements have been updated to include additional grants. A supplementary file is now provided for the data presented in Box 2 and a link to Pharos has been added.

https://doi.org/10.1038/s41573-019-0059-7 I Published online 8 January 2020

๑) Springer Nature Limited 2020 